\title{
Relato de Experiência do estágio de Ciências na forma de minicurso: resíduos sólidos e impactos socioambientais
}

\author{
Jumara Palma Nascimento \\ Lucas Silva de Almeida \\ Roberta Pereira dos Santos \\ Maria da Glória \\ Silvana do Nascimento Silva
}

\section{Resumo}

Entre as atividades propostas para estágios supervisionados na disciplina Metodologia do Ensino de Ciências, encontra-se o minicurso, modalidade adotada por um grupo de estagiários para trabalhar, em uma escola estadual do Sudoeste da Bahia, com os temas resíduos sólidos e impactos socioambientais, escolhido em virtude da familiaridade dos estagiários com a Educação ambiental, pela participação de todos em projetos de pesquisas, e também pela necessidade de se trabalhar questões ambientais com os alunos, por constituírem objetos das aulas de uma turma de doze alunos do nono ano do Ensino Fundamental. Ao longo de quatro encontros, as práticas selecionadas os envolveram, atraindo seu olhar crítico para problemas socioambientais, de modo que o minicurso constituiu uma experiência significativa, apesar de dificuldades geradas pela falta de costume da turma com interação dialógica em sala de aula. Todos os alunos saíram do curso com a sensação de dever cumprido, pois a timidez não impediu de problematizar os temas nem de socializar com colegas e estagiários. Desta forma, o minicurso acrescentou tanto à experiência de estágio, como à experiência de novas práticas, já que professores devem sempre estar abertos e preparados para renovar-se, usando novas práticas pedagógicas.

Palavras-chave: Educação ambiental. Estágio. Minicurso. Ensino de Ciências 


\title{
Experience report of the Science internship in the form of a short course: solid waste and socio-evironmental impacts
}

\author{
Jumara Palma Nascimento \\ Lucas Silva de Almeida \\ Roberta Pereira dos Santos \\ Maria da Glória \\ Silvana do Nascimento Silva
}

\begin{abstract}
Among the activities proposed for supervised internships in the Science Teaching Methodology discipline, there is the mini-course, an option adopted by a group of interns to work in a state school in the Southwest of Bahia, with the theme of solid waste and environmental impacts, chosen due to the interns' familiarity with environmental education, the participation of everyone in research projects, and also the need to work on environmental issues with students, as they are objects of classes for a class of twelve students in the ninth grade of elementary school. Throughout four meetings, the selected practices involved them, attracting their critical eye to socioenvironmental problems, so that the mini-course was a positive experience, despite difficulties generated by the class's lack of custom with dialogical interaction in the classroom. All students left the course with a sense of accomplishment, as shyness did not prevent them from problematizing the topics or socializing with colleagues and interns. In this way, the mini-course added a lot, both to the internship experience and to the experience of new practices, since teachers must always be open and prepared to renew themselves, using new pedagogical practices.
\end{abstract}

Keywords: Environmental Education. Phase. Short Course. Science teaching. 


\section{Introdução}

O presente artigo relata experiências e atividades desenvolvidas em um minicurso sobre os temas Resíduos sólidos e impactos socioambientais, realizado como forma de estágio supervisionado de Ciências Naturais, vinculado à disciplina Metodologia do Ensino de Ciências, do curso de Licenciatura em Biologia da Universidade Estadual do Sudoeste da Bahia (Uesb).

O estágio curricular constitui um importante instrumento de conhecimento e de integração do aluno na realidade social, econômica e do trabalho em sua área, para o processo de formação construção da identidade profissional (GARIGLIO et al, 2020).

Segundo Castells (apud BRZEZINSKI, 2002, p. 8-9),

[...] todos os componentes necessários para a construção da identidade, quer seja pessoal, quer seja coletiva, são processados pelos sujeitos e pelos grupos sociais que reorganizam significados conforme a influência das tendências sociais e dos projetos culturais, enraizados na sociedade.

Desta maneira, o estágio, em educação, é de grande relevância, pois assegura ações mais comprometidas com o processo educativo, tornando-se, com isso, o componente fundamental na construção da identidade do professor (FONSECA; GALVÃO, 2018). É através dele que estabelecemos relação entre a teoria e a prática, com base no princípio metodológico de que o desenvolvimento de competências profissionais implica em utilizar conhecimentos adquiridos (SANTOS, 2017), na vida acadêmica, profissional e pessoal, através da oportunidade de vivenciar tudo aquilo que aprendemos em sala de aula (GARIGLIO et al, 2020). Nesse sentido, Pimenta (1995, p.24) defende que "a atividade teórico-prática de ensinar constitui o núcleo do trabalho docente".

Além disso, o estágio curricular contribui para a formação da reflexão dos conteúdos das diversas disciplinas apresentados durante a licenciatura, desenvolvida no decorrer das ações vivenciadas, numa perspectiva reflexiva e crítica, através da oportunidade de conhecer e analisar a atuação do profissional da educação em sua ação pedagógica, bem como suas práticas e formas de agir dentro de uma sala de aula e da realidade dos alunos no contexto escolar. Desse modo, "o sujeito toma sua própria ação, seus próprios funcionamentos psíquicos como objeto de sua observação e de sua análise; ele tenta perceber e compreender sua própria maneira de pensar e agir" (PERRENOUD et al. , 2001, p. 174).

Barreiro e Gebran (2006, p. 22) enfatizam que

A aquisição e a construção de uma postura reflexiva pressupõem um exercício constante entre a utilização dos conhecimentos de natureza teórica e prática na ação e a elaboração de novos saberes, a partir da ação docente. A articulação da relação entre teoria e prática é um processo definidor da qualidade da formação inicial e continuada do professor, como sujeito autônomo na construção de sua profissionalização docente, porque lhe permite uma permanente investigação e a busca de respostas aos fenômenos e às contradições vivenciadas. [...] 
Assim, o estágio torna-se importante para a formação inicial, através da investigação da realidade por uma prática intencional, marcada por processos reflexivos, por meio da experiência vivenciada, ao observar, examinar, questionar e avaliar criticamente, a teoria e a prática (GARIGLIO et al, 2020).

O estágio, objeto deste relato, teve como objetivos: propiciar ao aluno (licenciando) o contato direto com a realidade de trabalho para a qual está sendo formado; proporcionar uma experiência acadêmico-profissional através de vivências no campo de prática; possibilitar reflexão, análise e questionamento sobre a realidade profissional; incorporar novos conhecimentos e habilidades úteis ao exercício da profissão docente; estabelecer relações entre a teoria e a prática e aperfeiçoar habilidades necessárias ao exercício profissional, além de elaborar relatório geral de estágio, com as experiências vivenciadas em campo através do minicurso.

\section{O estágio de ciências como propulsor da abordagem de temas socioambientais}

Pela aproximação dos licenciandos com o campo da Educação ambiental ao longo da execução de projetos de pesquisa e, também, tendo em vista a necessidade observada através de discussões nas disciplinas responsáveis pelo estágio de se trabalhar as questões socioambientais com os alunos do ensino fundamental, os temas escolhidos foram Resíduos sólidos e impactos ambientais.

Partindo da constatação que no contexto educacional ainda se encontram práticas pedagógicas pontuais e naturalísticas em educação ambiental, Carvalho (2008) argumenta a favor da necessidade da abordagem que preconiza que as questões socioambientais devem ser relacionadas com as diversas dimensões que permeiam a sociedade.

Silva (2012, p.49) destaca que

O processo educativo tem um papel preponderante na compreensão da relação entre homem, ambiente, sociedade, cultura e tecnologia, promovendo discussões e debates sobre a prudência no uso dos recursos naturais na sociedade contemporânea.

Isso adquire grande relevância, principalmente quando passamos a analisar a realidade dos jovens brasileiros, que são levados pelo sistema vigente a adotar o comportamento vinculado ao consumismo acelerado (SILVA; DOMINGOS, 2019). Podemos, para exemplificar, analisar a seguinte situação: com o aumento das novas tecnologias, às vezes um aparelho deixa de ser bom aos seus olhos, apenas por ter saído uma nova versão dele com algo significativamente melhor. Contudo, é ‘necessário' adquirir tal tecnologia para se sentir inserido em determinados grupos sociais e se sentir detentor de determinado status. 
Acreditamos que a partir de situações como essa, que colidem com tantos problemas socioambientais, é preciso formar alunos críticos, socioambientalmente responsáveis (SILVA; EL-HANI, 2014).

Nessa perspectiva, o estágio em forma de minicurso foi pensando em cinco encontros que contemplassem debates que envolvessem os alunos de forma atrativa e, ao mesmo tempo, pudéssemos levá-los a desenvolver um olhar crítico e ver o quanto o consumismo exacerbado pode causar mudanças drásticas e negativas ao meio ambiente (SANTOS, 2019).

A maior preocupação foi trabalhar com a educação ambiental crítica (LOUREIRO, 2004), pautada na abordagem dos aspectos sociais, políticos, econômicos, éticos, dentre outros. Nossa meta era apresentar as questões socioambientais dentro de um contexto dinâmico, permeado por ideologias, jogos de interesse e conflitos (CARVALHO, 2002; SILVA; EL-HANI, 2014).

Nesse contexto, as ações desenvolvidas no âmbito da Educação ambiental crítica devem ir além de demonstrar, por exemplo, como realizar a reciclagem, mas, antes de usá-la como alternativa de ambiente sustentável, é necessário se preocupar em analisar o processo de produção e combater o consumismo (LAYRARGUES, 2002; LAYRARGUES; LIMA. 2014).

\section{Organização e elaboração do estágio de ciência em forma de minicurso}

O estágio de Ciências em forma de minicurso foi comprendidido "como uma atividade-eixo... que sustenta e permeia todo o percurso do ensinar e do aprender" (PIMENTA; LIMA, 2004, p.180). O minicurso foi realizado pelos quatros primeiros autores deste artigo, que, na época, eram licenciandos em Ciências Biológicas e cursavam a disciplina Práticas e Metodologia de Ciências Naturais.

A escola na qual o minicurso foi realizado faz parte da rede pública estadual de ensino. A atividade destinou-se a uma classe do nono ano do ensino fundamental que tinha doze alunos.

No processo do planejamento, primeiro foi escolhido o tema, logo após, foi elaborada a proposta pedagógica. De início, o tema idealizado pelo grupo foi Resíduos sólidos e a escola, levando em consideração a repercussão que a mídia dá às questões ambientais, por ter uma relevância social significativa. Mas, no decorrer das reuniões para a elaboração do plano de aula, decidimo-nos pelos temas Resíduos sólidos e impactos socioambientais, por apresentar a possibilidade de debates sobre a relação ser humano-sociedade-natureza (SANTOS, 2019). Por esta razão, pensamos em adotar uma postura individual ou coletiva, de conferir destaque às práticas que resultassem em benefício para a sociedade e meio ambiente, debatendo com os alunos os impactos negativos causados pela produção excessiva de resíduos sólidos gerados pelo consumismo (LAYRARGUES; LIMA. 2014). 
O planejamento do minicurso foi produzido em grupo, através da elaboração do plano de aula baseado na utilização de conteúdos e ações conceituais, procedimentais e atitudinais (POZO; CRESPO, 2009) para as escolhas dos subtemas, objetivos e dos materiais que seriam utilizados em cada dia. Os subtemas abordados foram: Produção e consumo dos resíduos sólidos; Impactos socioambientais dos resíduos sólidos; A importância da coleta seletiva; A necessidade da reciclagem e Formas de reciclagem.

O minicurso, voltado para os temas Resíduos sólidos e impactos socioambientais, teve como objetivo principal contribuir para a formação de alunos críticos e capazes de enxergar a necessidade de aprimorar suas práticas para melhorar o quadro ambiental, que atualmente é de consumo descontrolado, descarte irresponsável e utilização inadequada dos recursos naturais (LOUREIRO, 2019). O minicurso foi desenvolvido em cinco encontros de 4 horas cada, perfazendo um total de 20 horas.

\section{Planejamento em ação: primeiro encontro}

No primeiro encontro, o conteúdo abordado foi Produção e consumo de resíduos sólidos. Iniciou-se com a dinâmica da sala suja (Figura 1) em que ao entrar, os participantes deparavam-se com diversos tipos de lixo que estavam espalhados pelo chão e pelas mesas da sala, com o intuito de introduzir o debate que deveria problematizar o impacto provocado pela produção e pelo descarte de resíduos sólidos. O objetivo da dinâmica era fazê-los refletir a respeito da produção demasiada de produtos e seus resíduos e debater as consequências, para a natureza, dessa produção desenfreada de indústrias e dos latifundiários.

Figura 1: Dinâmica da sala suja, com problematização: produção de resíduos sólidos e de lixo.

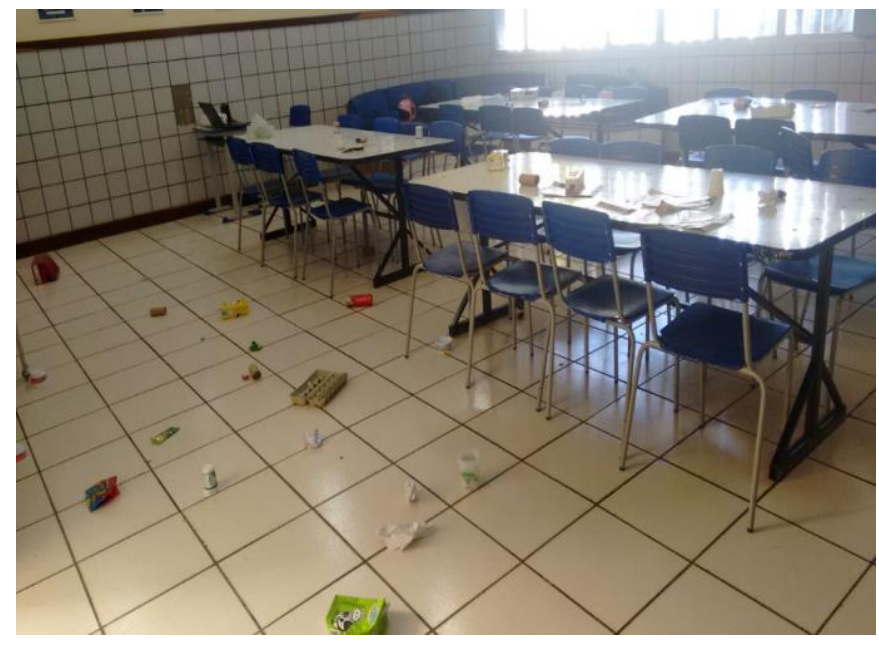

Fonte: Acervo dos autores, 2016

Em seguida, foi realizada uma aula dialogada, através de leitura de texto e apresentação de slides, com imagens relacionadas ao tema, com o objetivo de abordar a cultura de consumo da sociedade atual e a pressão psicológica exercida sobre as pessoas para que, 
muitas vezes inconscientemente, sintam-se obrigados(as) a comprar (SILVA, LOUREIRO, 2019). Por fim, foi desenvolvida uma Dinâmica do "repolho" (Figura 2) onde é montada uma estrutura em forma de repolho formada com várias camadas de figuras contendo charges, imagens, pequenas frases de impacto para interpretação e perguntas, com o intuito dos estudantes exporem suas visões sobre o consumismo e a produção desenfreada.

Ao entrar na sala os alunos se mostraram surpresos com a quantidade de lixo espalhado pelo ambiente e questionaram o porquê da sala estar tão suja. Em cima desse questionamento foi feito uma problematização sobre o descarte dos resíduos e o respeito pelo ambiente e pelos profissionais que cuidam da faxina da escola. Alguns estudantes se mostraram bem à vontade para participar das dinâmicas e foram capazes de construir opiniões críticas e reflexivas acerca das atitudes da sociedade (LOUREIRO, 2019), inclusive as próprias atitudes em relação ao impulso pela compra de aparelhos eletrônicos apenas pela necessidade de ter um produto de modelo mais atual e ter uma boa impressão no grupo de amigos. Foi uma surpresa muito agradável para nosso grupo, uma vez que, não imaginávamos uma boa recepção, pois éramos ainda pessoas externas a eles e que o primeiro contato causaria estranhamento.

Figura 2: Dinâmica do repolho: produção e consumo

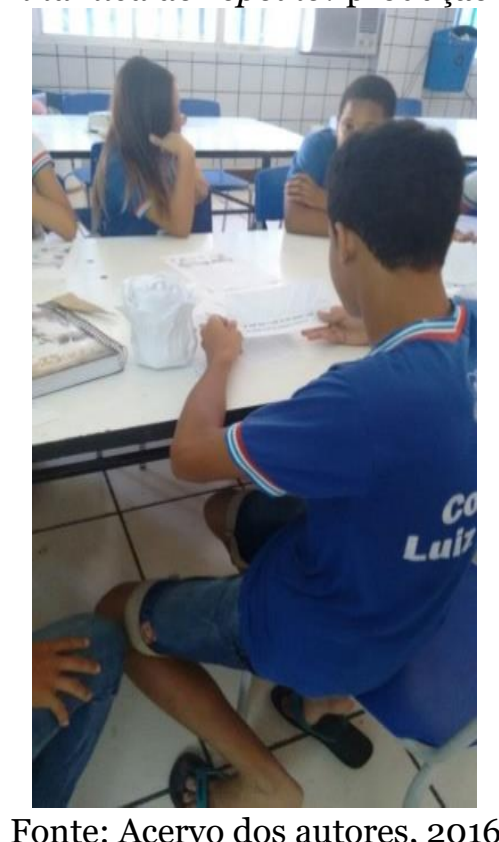

\section{Segundo encontro}

No segundo encontro, o conteúdo abordado foi os Impactos socioambientais dos resíduos sólidos. Este iniciou-se com um momento de conversa com os alunos, durante o qual, eles pegaram um bombom com uma palavra referente a um impacto ambiental, trazendo conhecimento prévio sobre o assunto, com o objetivo de dialogar sobre os impactos causados pela produção desenfreada, o consumo de produtos e o descarte dos resíduos sólidos 
(LAYRARGUES; LIMA. 2014).

Logo após, foi exibido um filme, A história das $\operatorname{coisas}^{13}$, que é um documentário de 20 (vinte) minutos, apresentado por Annie Leonard que trata a origem das coisas que compramos para o nosso bem estar, e mostra que a responsabilidade do cuidado com o meio ambiente é bem complexo e exige participação responsável de toda a sociedade (SILVA; ELHANI, 2014), inclusive dos governantes, que são os maiores responsáveis pela produção exagerada de produtos e o descarte irresponsável (SILVA, 2019). A fim de dar sequência ao minicurso, houve a apresentação de slides sobre o trabalho infantil ou o trabalho escravo. Em seguida, foi desenvolvida uma roda de conversa (Figura 3) para discussão sobre o consumismo e as técnicas equivocadas e perniciosas de empresas para obter lucros cada vez maiores (SILVA; LOUREIRO, 2019). Nesse ponto, destacaram-se as indústrias de diversas marcas de produtos que utilizam trabalho infantil ou escravo, como mão de obra barata para produzirem mais lucro.

Figura 3: Roda de conversa: problematização sobre os impactos ambientais

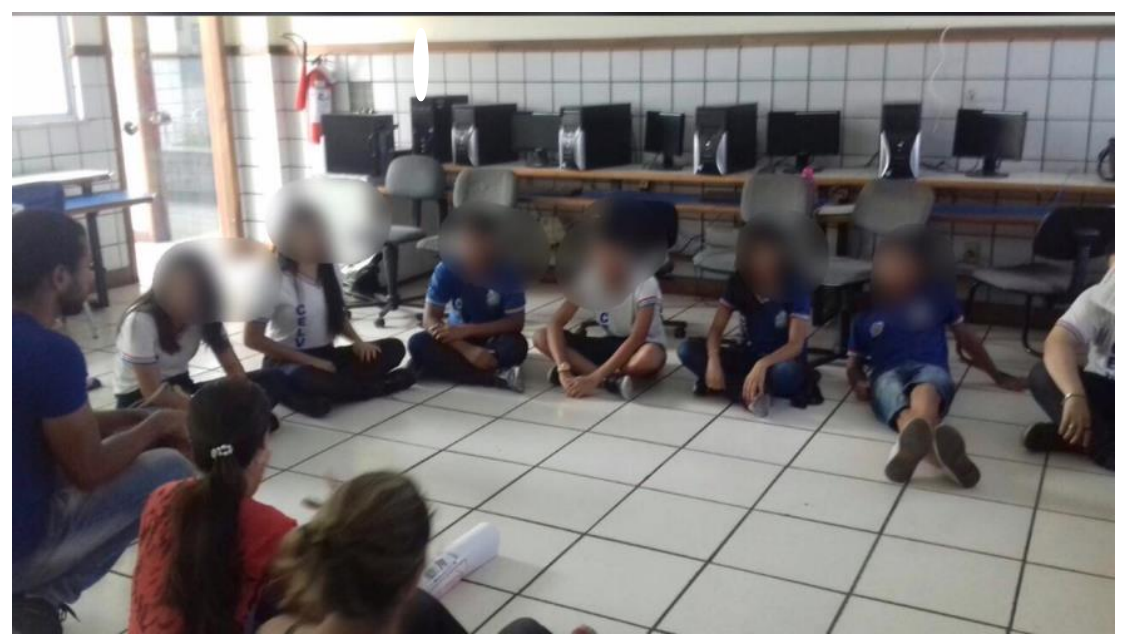

Fonte: Acervo dos autores, 2016

Depois, foi exibido um vídeo da música $A b s u r d o^{14}$, de Vanessa da Mata, com o objetivo de problematizar com os participantes sobre a necessidade de redução de resíduos sólidos. Para finalizar, realizou-se um jogo de quebra-cabeça com temas relacionados às doenças de veiculação hídrica.

\section{Terceiro encontro:}

No terceiro encontro, discutimos A importância da coleta seletiva. Iniciou-se com o debate sobre a importância da coleta seletiva (SANTOS et al, 2017), e o que pode ocorrer nas regiões que não possuem esse mecanismo. Por fim, fechamos as discussões com a análise do

${ }^{13}$ História das Coisas - https://www.youtube.com/watch?v=xBCoc842FV8\&feature=youtu.be $14 \mathrm{https}$ ://www.youtube.com/watch?v=ZxSbVM9IOzA\&feature=youtu.be ISSN 2526-2882

$$
\text { *259* }
$$


município de Jequié-BA em relação à coleta seletiva e apresentamos, em forma de slides, curiosidades sobre o tema.

Com base nessas discussões, constituíram-se grupos de participantes para a confecção de caixas de coleta seletiva. Quando a confecção terminou, cada grupo explicou aos demais em que consistia o resíduo correspondente à sua caixinha.

Em seguida, realizamos com eles a leitura dos textos: Sustentabilidade: desenvolvimento presente garantindo o futuro das próximas gerações e Os 5 rs da sustentabilidade. Após a leitura, foi iniciada uma discussão, na qual tentamos deixar nítido para eles que, antes de pensar em reciclar, devemos nos preocupar em reduzir (SANTOS et al, 2017).

Para finalizar nosso encontro desse dia, aos mesmos grupos foi dada a tarefa de montar cartazes (Figura 4) sobre os impactos ambientais e apresentarem à turma. Na elaboração, os participantes foram deixados bem à vontade para usarem a criatividade.

Figura 4: Apresentação de painéis confeccionados em sala sobre impactos ambientais.

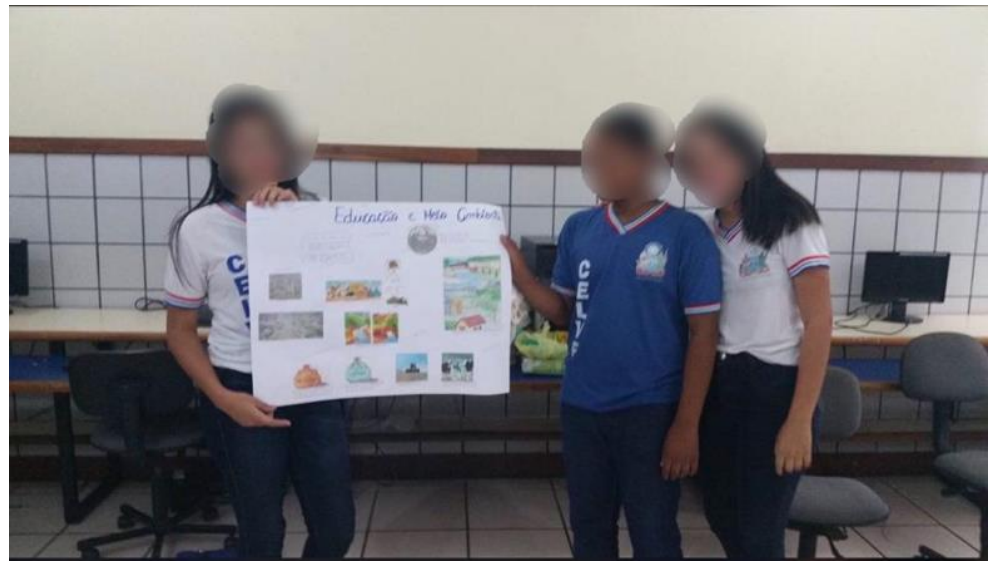

Fonte: Acervo dos autores, 2016

Com todas essas informações, um dos alunos expressou a curiosidade de saber onde vão parar as pilhas e baterias, e os estagiários ficaram de trazer um texto explicativo no próximo encontro.

Esse momento foi muito importante, pois trabalhou o discurso e o argumento dos alunos e nos surpreendeu, pois não imaginávamos que eles estariam tão à vontade para debater e apresentar um trabalho expositivo para seus colegas de classe. Isso nos fez perceber que temos que apostar no potencial dos nossos estudantes e motivá-los com atividades diversas que explorem os pontos positivos de cada um.

\section{Quarto encontro}

O quarto encontro teve como tema principal o debate sobre $A$ necessidade de reciclagem. Para sanar a curiosidade de um dos alunos, um dos estagiários apresentou e ISSN 2526-2882 
discutiu um texto que explicava o destino de pilhas e baterias, Depois, eles foram separados em grupo, para que pudessem ler uma parte do texto e explicar em seguida.

Logo após, os alunos assistiram aos vídeos: De onde vem o papel?15, De onde vem o vidro? ${ }^{16}$, De onde vem o plástico? ${ }^{17}$, De onde vem a energia elétrica ${ }^{18}$ ?.

Com o intuito de propor alternativas de reciclagem, realizamos exposição em slides, apresentando ideias de objetos com materiais reutilizados, não nos esquecendo de mostrar a eles que é possível reduzir o consumo desenfreado (LAYRARGUES; LIMA. 2014).

Figura 5: Reciclagem de resíduos sólidos

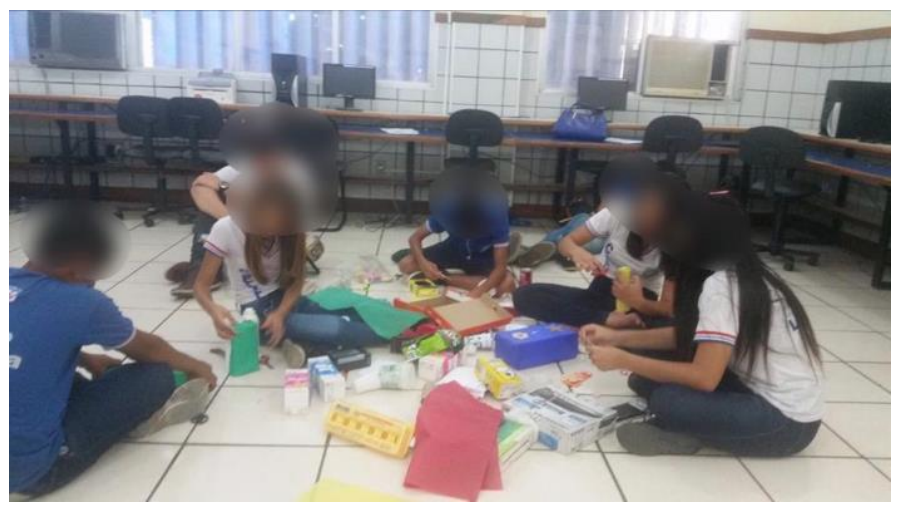

Fonte: Acervo dos autores, 2016

Para finalizar nosso encontro, deixamos que colocassem "a mão na massa" e usassem sua criatividade para confeccionar objetos com os resíduos sólidos que eles mesmos trouxeram de casa (Figura 5).

\section{Quinto encontro}

Iniciamos o quinto encontro com uma conversa informal com os alunos, revisando os conteúdos abordados anteriormente. Desta vez, eles expuseram suas opiniões e mostraram os conhecimentos adquiridos durante a realização do minicurso. Depois foi passado um vídeo da música Herdeiros do futuro ${ }^{19}$ de Toquinho, com o propósito de fazer com que os alunos, mais uma vez, refletissem sobre a necessidade de cuidar do nosso planeta (LOUREIRO, 2019). Em seguida, realizamos um debate a respeito da letra da música.

Logo após, expusemos um slide contendo tópicos do que foi abordado em aulas anteriores, e os alunos falaram o que tinham entendido, e como esse conteúdo tinha mudado sua maneira de observar as questões do dia a dia, relacionando-as com os assuntos trabalhados.

\footnotetext{
15 De onde vem o papel? https://youtu.be/rjUaQWoVGok

${ }_{16}$ De onde vem o vidro? https://youtu.be/gjoR3nmB67Q

17 De onde vem plástico? https://youtu.be/uVoRof1sy4Q

18 De onde vem à energia elétrica? https://youtu.be/8ti6FtlvMoc

19 Herdeiros do futuro - https://youtu.be/IGMpuo_a5zU ISSN 2526-2882 
Finalizamos o minicurso com uma roda de conversa e cada um discorreu sobre o que aprendeu, e de que forma os assuntos trabalhados os fizeram pensar de forma crítica, conteúdos do cotidiano, que antes era visto de forma superficial.

\section{Conhecimentos adquiridos no desenvolvimento do minicurso}

O minicurso, como estratégia de estágio na formação inicial, foi uma experiência muito significativa, pois foi possível refletir sobre a prática docente e colocar em prática os conhecimentos teóricos apresentados durante a nossa caminhada na licenciatura (PIMENTA; LIMA, 2004). Foi uma experiência plenamente satisfatória que nos fez perceber como que teoria e prática combinam no ensino e na aprendizagem em diversas situações.

Além disso, a experiência nos proporcionou a aproximação com a realidade escolar, para que possamos perceber os desafios que a carreira docente pode oferecer, refletindo sobre a profissão e obtendo (in)formações e trocas de experiências (GARIGLIO et al, 2020).

A partir daí, percebemos que os conhecimentos trabalhados e adquiridos em sala de aula, durante a disciplina, e as experiências vivenciadas no minicurso nos permitiram construir conhecimentos e obter experiências valiosas, contribuindo bastante em nosso desenvolvimento como futuros profissionais da educação (FONSECA; GALVÃO, 2018).

Nesse sentido, Pimenta e Ghedin (2002, p. 24) argumentam

[...] que o saber docente não é formado apenas da prática, sendo também nutrido pelas teorias da educação. A teoria tem importância fundamental na formação dos docentes, pois dota os sujeitos de variados pontos de vista para uma ação contextualizada, oferecendo perspectivas de análise para que os professores compreendam os contextos históricos, sociais, culturais organizacionais e de si próprios como profissionais. (o tamanho da fonte foge ao recomendado pela revista).

E, partindo desse olhar, verificamos que o estágio em forma de minicurso nos proporcionou, como futuros profissionais de educação, compreender a complexidade que envolve os diferentes contextos educacionais, a ponto de estabelecer uma relação dialógica com as práticas institucionais e as ações vivenciadas no âmbito escolar (GARIGLIO et al, 2020).

Com isso, é possível afirmar que a realização do minicurso foi de suma importância para nossa formação inicial, pois nos preparou, de certa forma, para o exercício da profissão e esse estágio veio contribuir para o aprofundamento e a prática do apreendido em sala de aula (PIMENTA; LIMA, 2004). Essa formação cria expectativas positivas diante da profissão, proporcionando a construção de uma concepção de ciência e de ensino de ciências firmada na descoberta (SILVA; SILVA, 2018), na relação com a realidade profissional e tudo que foi abordado no curso de licenciatura. 


\section{Pedras no caminho}

Como pedra no caminho a nossa única dificuldade em relação à execução foi a falta de participação de alguns alunos. Às vezes por timidez, outras, por desconhecimento do assunto, ou porque tinham medo de falar algo errado. Sempre tentamos mostrar a eles, porém, que não existia certo ou errado, que estávamos ali para construirmos o conhecimento em colaboração (SANTOS, 2017).

No final, nosso trabalho foi gratificante, pois o índice de frequência foi satisfatório: foram 14 alunos matriculados e 12 frequentadores, ou seja, houve apenas evasão de dois alunos, deixando-nos satisfeitos pela importância que deram ao tema.

Pode-se afirmar que não houve dificuldades em relacionar o tema com os aspectos socioambientais, uma vez que já que existe uma grande relação entre ambos, pois abordar produção e descarte de resíduos sólidos sempre nos leva a discutir os aspectos socioambientais que os acompanham, isto é, a inclusão social/responsabilidade social e sustentabilidade.

\section{Considerações}

A realização do estágio através do minicurso é um momento diferenciado na formação acadêmica, pois possibilita ao licenciando pôr em prática seus conhecimentos, fazendo-o sentir o que é a profissão de educador e que, apesar das dificuldades, nós podemos vencer determinados obstáculos (SANTOS, 2017). Na verdade, ser educador é estar disposto a lutar a cada dia de aula, superando as dificuldades, o salário baixo, a falta de apoio, de recursos pedagógicos e, principalmente, a ter confiança e contribuir para a formação de cidadãos críticos e reflexivos que se iniciam seu desenvolvimento através da escola e do ensino.

Durante o desenvolvimento do minicurso, sentimos que, à medida que realizávamos cada encontro, adquiríamos experiências e uma maneira diferente de pensar no que realmente seria a profissão que nós escolhemos. Percebemos que o estágio é associação da teoria-prática pela qual o futuro profissional da educação vai conhecer seu mundo, ou seja, o campo em que vai atuar (SANTOS, 2017).

Dessa forma, pensamos que as atividades do minicurso nos deram a oportunidade de expressar realmente a profissão de educar/ensinar e colocar em prática as questões éticas, respeito aos nossos estudantes e a aproximação com o ambiente escolar. A ação e a reflexão sobre o que realizamos no nosso dia a dia na escola e tudo o que aprendemos, desde as abordagens e discussões, trouxeram uma fundamentação educacional, novos desafios, reflexões e descobertas (SILVA; SILVA, 2018).

A utilização de minicurso como ferramenta de ensino nos permitiu observar outra forma de se trabalhar e problematizar temas transversais na sala de aula, pois, durante sua realização, foi possível associar a educação ambiental a vários ambientes e perspectivas, 
acrescentando de forma singular, tanto academicamente falando, como na condição de pessoa humana (SANTOS, 2017).

Termos a oportunidade de discutir temas tão importantes em grupo enriqueceu nossa formação como professores e como seres humanos em relação a questões socioambientais (PIMENTA; LIMA, 2004). Por se ter constituído como trabalho em equipe, o minicurso contribuiu para o fortalecimento do grupo em relação ao respeito ao ponto de vista um do outro. Sabemos que as salas de aulas já não são tão fáceis, como já foram um dia: encontramos alunos desinteressados, que não respeitam os professores e, por isso, nós, professores em formação, ficamos com receio do que podíamos enfrentar no estágio, por se tratar de uma atividade fora do contexto a que eles estão acostumados a vivenciar. Mas, no final, nossos temores não se confirmaram e a experiência foi positiva.

E em relação ao âmbito pessoal, deu-nos sensação de satisfação, pois nos sentimos capazes de fazer algo pelo nosso planeta. Nesse período, mediamos conhecimentos para esses alunos e acreditamos que conseguimos atingir nosso objetivo principal: abrir seus horizontes quanto às questões socioambientais (SANTOS, 2019).

Plantamos nossa semente, esperando que esse conhecimento possa ser compartilhado adiante, fazendo com que todos façam sua parte, mesmo que pareça ser algo pequeno, pois uma atitude faz toda diferença.

Necessitamos de uma educação ambiental renovada, crítica, pois o mundo pede nosso cuidado diário (LOUREIRO, 2019).

\section{Referências}

A HISTÓRIA DAS COISAS (Dublado) “The Story Of Stuff”. A história das coisas apresentado por Annie Leonard. [S.L.:s.n], 2013. 1 vídeo (21 min 18 seg). Publicado pelo Canal de Gustavo Mello. Disponível em: https://youtu.be/xBCoc842FV8. Acesso em: 6 de Março de 2016.

ABSURDO- VANESSA DA MATA. Absurdo apresentado por Vanessa da Mata. [S.L.:s.n], 2009. 1 vídeo (3 min 29 seg). Publicado pelo Canal de Patrícia Borges. Disponível em: https://youtu.be/ZxSbVM9IOzA. Acesso em: 10 de Março 2016.

BARREIRO, I. M. F.; Gebran, R. A. Prática de ensino e estágio supervisionado na formação de professores. São Paulo: Avercamp, 2006.

BRZEZINSKI, I. Pedagogia, pedagogos e formação de professores: a busca e movimento. Campinas: Papirus, 1996.

CARVALHO, I. C. de M. A questão ambiental e a emergência de um campo de ação políticopedagógica. In: LOUREIRO, C. F. B; LAYRAGUES, P. P; CASTRO, R. S. (Org.). Sociedade e meio ambiente: a educação ambiental em debate. São Paulo: Cortez, 2002. p.53-65. 
DE ONDE VEM A ENÉRGIA ELÉTRICA? \#Episodio 3. De onde vem à energia elétrica? apresentado por Kika. [S.L.:s.n], 2015.1 vídeo (3 min 53seg). Publicado pelo Canal De onde Vem, uma produção da TV PinGuim. Disponível em: https://youtu.be/8ti6FtlvMoc. Acesso em: 11 de Março 2016.

DE ONDE VEM O PAPEL? \#Episodio 15. De onde vem o papel? apresentado por Kika. [S.L.:s.n], 2015.1 vídeo (4 min 52seg). Publicado pelo Canal De onde Vem, uma produção da TV PinGuim. Disponível em: https://youtu.be/rjUaQWoVGok. Acesso em: 11 de Março 2016.

DE ONDE VEM O PLÁSTICO? \#Episodio 16. De onde vem o plástico? apresentado por Kika. [S.L.:s.n], 2015.1 vídeo (4 min o3seg). Publicado pelo Canal De onde Vem, uma produção da TV PinGuim. Disponível em: https://youtu.be/uVoRof1sy4Q. Acesso em: 11 de Março 2016.

DE ONDE VEM O VIDRO? \#Episodio 19. De onde vem o vidro? apresentado por Kika. [S.L.:s.n], 2015.1 vídeo (4 min 27seg). Publicado pelo Canal De onde Vem, uma produção da TV PinGuim. Disponível em: https://youtu.be/gj9R3nmB67Q. Acesso em: 11 de Março 2016.

FONSECA; M. R.; GALVÃO; L. C. M. S. O estágio supervisionado no ensino da Biologia: contribuições para formação docente. Anais... Educon, Aracaju, Volume 10, n. 01, p.1-8, set/2016, disponível em: http://anais.educonse.com.br/2016/o_estagio_supervisionado_no_ensino_da_bio logia_contribuicoes_para.pdf

GARIGLIO, J. A et al (org). A iniciação à docência na educação básica: dilemas e aprendizagens profissionais. Curitiba: Appris, 2020.

HERDEIROS DO FUTURO. Herdeiros do futuro apresentado por Leandro e Leonardo [S.L.:s.n], 2009. 1 vídeo ( 3 min 56seg). Publicado pelo canal Bruuhzinhaa, produzido pela professora Eliane Queiroz, do Autor Toquinho. Disponível em: https://youtu.be/IGMpuo_a5zU. Acesso em: 12 de Março 2016.

LAYRARGUES, P. P. O cinismo da reciclagem: o significado ideológico da reciclagem da lata de alumínio e suas implicações para a educação ambiental. In: LOUREIRO, C.F.B.; LAYRARGUES, P.P.;CASTRO, R. de S. (Org.). Educação ambiental: repensando o espaço da cidadania. São Paulo: Cortez, 2002. p. 179-219.

; LIMA, G. As macrotendências político-pedagógicas da Educação Ambiental brasileira. Ambiente \& Sociedade. São Paulo v. XVII, n. 1. p. 23-40, jan.mar. 2014.

LOUREIRO, C. B. F. Educação Ambiental: questões de vida. São Paulo: Cortez, 2019.

Trajetórias e fundamentos de educação ambiental. São Paulo: Cortez, 2004.

ISSN 2526-2882

$$
\text { * } 265 *
$$


PERRENOUD, P. et al. Formando professores profissionais: quais estratégias? Quais competências? 2. ed. Trad. Fátima Murad e Eunice Gruman. Porto Alegre: Artmed, 2001.

PIMENTA, S. G. Ghedin, E. (Org.). Professor reflexivo no Brasil. São Paulo: Cortez, 2002. . O estágio na formação de professores: unidade entre teoria e prática. INEP/ Relatos de pesquisa- Série documental, n. 25, , p.16-25, 1995. LIMA, M.S.L. Estágio e Docência. São Paulo: Cortez, 2004.

POZO, J. I.; CRESPO, M. A. G. A aprendizagem e o Ensino de Ciências: do conhecimento cotidiano ao conhecimento científico. Porto Alegre: Artmed, 2009.

SANTOS; C. R. A abordagem de temas socioambientais como forma de articulação entre educação ambiental crítica e ensino de ciências na percepção de professores do ensino fundamental. (Dissertação) Mestrado em Educação Científica e Formação de Professores da Universidade Estadual do Sudoeste da Bahia, Jequié, 2019.

SANTANA, T.; AZEVEDO, R.; PINHEIRO, P.; SILVA, S. N. Reciclagem de papel e o desenvolvimento de ações sustentáveis: uma parceria entre o Pibid interdisciplinar em Educação ambiental. Revista Brasileira de Educação Ambiental, v. 12, p. 114-126, 2017.

SANTOS, T. M. Uma proposta de estágio supervisionado em educação ambiental no curso de licenciatura em Ciências Biológicas. (Dissertação) Mestrado em Educação Científica e Formação de Professores da Universidade Estadual do Sudoeste da Bahia, Jequié, 2017.

SILVA, S. N. A BNCC da educação infantil ao ensino fundamental: políticas públicas currículo, competências e educação ambiental. Editora CRV: Curitiba, 2019.

O tema ambiente em um livro didático de biologia do ensino médio: uma análise à luz da teoria sociológica de Basil Bernstein. Tese (doutorado) Universidade Federal da Bahia, Instituto de Física. Universidade Estadual de Feira de Santana, 2012.

DOMINGOS, P. Mapeamento dos artigos apresentados no grupo de discussão de pesquisa Educação Ambiental no contexto escolar do EPEA de 2017. Revista Sergipana de Educação Ambiental, v 7, n 2, p. 73-82.

EL-HANI, C.A abordagem do tema ambiente e a formação do cidadão socioambientalmente responsável. Revista Brasileira de Pesquisa em Educação em Ciências. Rio de Janeiro, v. 14, n. 2, abr./jun. 2014.Número temático: Discursos Ambientais em Educação em Ciências: contribuições para a democracia, cidadania e justiça social, maio/agosto de 2014.Disponível 
em: < http://revistas.if.usp.br/rbpec/article/view/903/387>. Acesso em: 18 mar. 2016.

LOUREIRO, C. F. B. O sequestro da Educação Ambiental na BNCC (Educação Infantil - Ensino Fundamental): os temas Sustentabilidade/Sustentável a partir da Agenda 2030. In: XII ENPEC, 2019, Natal. XII Encontro Nacional de Pesquisa em Educação em Ciências. XII ENPEC, 2019. p. 1-7. Disponível em: https://abrapecnet.org.br/enpec/xii-enpec/anais/lista area 05 1.htm

SILVA, E. P.; SILVA, S. N. Estágio Supervisionado: análise dos artigos publicados nas Atas do Enpec. In: o VII ENEBIO - I EREBIO NORTE; Belém: IEMCI, UFPA, 2018, p. 23772385 .

https://sbenbio.org.br/wpcontent/uploads/anais/anais_vii_enebio_norte_completo_2018.pdf

\section{Biografia Resumida}

Jumara Palma Nascimento Serra: Licenciada em Ciências Biológicas pela Universidade Estadual do Suoeste da Bahia (UESB). Professora do Colégio Social em Jequié-BA.

Lattes: http://lattes.cnpq.br/8050491456333438

Contato: Marasabatny@hotmail.com

Lucas Silva de Almeida: Licenciado em Ciências Biológicas pela Universidade Estadual do Suoeste da Bahia (UESB). Professor efetivo da Rede Estadual da Bahia (SEC BA) da Escola Estadual Renan Baleiro em Salvador-BA.

Lattes: http://lattes.cnpq.br/4734039655776464

Contato: lucasalmeeida04@gmail.com

Roberta Pereira dos Santos: Licenciada em Ciências Biológicas pela Universidade Estadual do Suoeste da Bahia (UESB).

Lattes: http://lattes.cnpq.br/3760294452015590

Conatato: robertasantos-91@hotmail.com

Maria da Glória Querino: Licenciada em Ciências Biológicas pela Universidade Estadual do Suoeste da Bahia (UESB). Posgraduada em Neuropsicologia da Educação pela Faculdade ESEO. Professora contratada da Escola Municipal Maria Amélia Genê Pirajá em Itabuna-BA.

ISSN 2526-2882

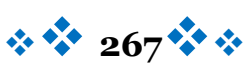


Lattes: http: http://lattes.cnpq.br/6772029630523330

Contatos: glorinha_querino@hotmail.com

Silvana do Nascimento Silva: Licenciada em Ciências Biológicas (UESB). Mestra em Ciências Biológicas (UFBA). Doutora em Ensino, Filosofia e História das Ciências (UFBA). Pós-doutorado em Educação (UFRJ). Professora Titular do Departamento de Ciências Biológicas e do Programa de Pós-graduação em Educação Científica e Formação de Professores (UESB). Líder do Grupo de Pesquisa em Educação Ambiental e Formação de Professores (GPEA-FP).

Lattes: http://lattes.cnpq.br/6605478190740111

Contato: siluesb@hotmail.com 